\title{
Percepção das mães em relação ao aleitamento materno no período do pós parto
}

Perception of mothers in relation to breastfeeding in the postpartum period

Karina Rodrigues Mendes da Aparecida ${ }^{1}$, Loide Corina Chaves ${ }^{1}$, Rosangela Filipini ${ }^{1}$, Isabel Cristine Fernandes ${ }^{1}$

${ }^{1}$ Curso de Graduação em Enfermagem da Faculdade de Medicina do ABC (FMABC) - Santo André (SP), Brasil.

DOI: http://dx.doi.org/10.7322/abcshs.v39i3.648

\section{RESUMO}

Introdução: Para eficácia do aleitamento materno, a Organização Mundial de Saúde propõe a educação das mães durante o momento da gestação pelos profissionais de saúde. Objetivo: Observar as percepções das mães com relação ao aleitamento materno. Métodos: Estudo descritivo de caráter quantitativo utilizando técnica exploratória. Pesquisa realizada no Centro de Saúde Escola Capuava em Santo André, São Paulo. A população foi constituída por 29 mães submetidas à primeira consulta puerperal. Resultados: As médias de idade e de número de filhos das mães foram 26 anos e 1,8 filhos. Em sua maioria são casadas ou encontra-se em união estável (93,1\%) e apresentam ensino médio completo (62,1\%). Possuem vínculo empregatício 51,7\%. Teve parto cesárea 58,6\%. Foram amamentados na sala de parto 69,0\% dos recém-nascidos. Possuem mamilos protusos $79,3 \%$ das mães, sendo que $55,2 \%$ não apresentaram fissuras. Não apresentaram nenhum cuidado em relação à limpeza dos mamilos $37,9 \%$ das mães, as demais usaram várias formas, sendo mais comum somente limpeza com leite materno $(17,2 \%)$ e somente utilização de pomada $(13,8 \%)$. A frequência de amamentação foi bastante variável. Dos recémnascidos, 89,3\% apresentaram pegas corretas. Relataram que tiveram todas as informações necessárias no pré-natal e puerpério 96,6\% das mães. Pretendem introduzir precocemente o uso de chupetas para seu recém-nascido $44,8 \%$ das mães. Conclusão: As orientações realizadas durante a gestação e puerpério se tornam importantes e aos poucos produzem resultados positivos. Vale enfatizar que o enfermeiro se torna uma peça chave na realização das orientações durante os períodos de gestação e puerpério.

Palavras-chave: aleitamento materno; promoção da saúde; recémnascido; mães.

\begin{abstract}
Introduction: In order to achieve breastfeeding efficiency, World Health Organization proposes education of mothers during pregnancy by health care professionals. Objective: To observe the perceptions of mothers regarding breastfeeding. Methods: Descriptive quantitative study following exploratory technique. Research was carried out at the Centro de Saúde Escola Capuava in Santo André, São Paulo, Brazil. The population consisted of 29 mothers submitted to the first postpartum visit. Results: The mean age of mothers was 26 years and the mean number of children was 1.8. Most of them are married or have stable union (93.1\%) and completed high school (62.1\%). A total of $51.7 \%$ are currently employed; $58.6 \%$ had cesarean section. Most $(69.0 \%)$ of newborns were breastfed in the delivery room. Of mothers, $79.3 \%$ have protruding nipples, and $55.2 \%$ showed no fissures; $37.9 \%$ did not have any care regarding nipple cleaning, the remaining used various procedures, most commonly breast milk alone (17.2\%) and ointment alone (13.8\%). The frequency of breastfeeding was quite variable. Of newborns $89.3 \%$ presented correct latch. Of mothers, $96.6 \%$ reported receiving all the necessary information in the prenata and postpartum; $44.8 \%$ intend to early introduce pacifier for their newborn. Conclusion: The instructions given during pregnancy and postpartum become important and gradually produce positive results, it is worth emphasizing that the nurse becomes a key part in achieving the guidelines during pregnancy and postpartum periods.
\end{abstract}

Keywords: breast feeding; health promotion; infant, newborn; mothers.

Recebido em: 18/09/2013

Revisado em: 12/05/2014

Aprovado em: 14/07/2014

Autor para correspondência: Karina Rodrigues Mendes da Aparecida - Avenida Príncipe de Gales, 821 - Príncipe de Gales - CEP: $09060-650$ Santo André (SP), Brasil - E-mail: karinaaparecida12@hotmail.com

Conflito de interesses: nada a declarar. 


\section{INTRODUÇÃO}

A Organização Mundial de Saúde (OMS) recomenda o aleitamento materno exclusivo (AME) durante os seis primeiros meses de vida. Em países em desenvolvimento, entre 1990 e 2000, as taxas de AME em crianças com menos de 4 meses aumentaram cerca de $15 \%$, sendo, também, mais evidente nas zonas urbanas. Na maioria dos países desenvolvidos, as taxas de iniciação do aleitamento materno são superiores a $90 \%$, diminuindo significativamente até aos 6 meses, observando-se, nesse momento, o AME em menos de $25 \%$ das crianças. No Brasil, com o intuito da promoção e proteção do aleitamento materno (AM), criou-se o Instituto Nacional de Alimentação e Nutrição e o Programa Nacional de Incentivo ao Aleitamento. O governo estipulou licença maternidade, alojamento conjunto, implantação de Bancos de Leite Humano e grupos de apoio à amamentação. Em 1990 foi criada a Iniciativa do Hospital Amigo da Criança, na qual foram desenvolvidos os dez passos para o AM, e os novos termos de tipos de AM pela OMS definidos em 1997 como AME, predominante e artificial ${ }^{1,2}$.

Um meio de promover e incentivar o AM são a iniciativa logo após o parto, quando o período de reatividade do recém-nascido (RN) está presente, fortalecendo o vínculo entre mãe e bebê, reduzindo a mortalidade neonatal e materna, pois diminui hemorragias e favorece a involução uterina. Apesar desse contexto estabelecido pela OMS, a amamentação na primeira hora de vida é baixa em muitas maternidades. Segundo estudos, em $43 \%$ dos casos o AM inicia em sala de parto. Muitos desses aspectos negativos para aderência estão relacionados a questões estruturais, sejam elas físicas ou de recursos humanos ${ }^{3-5}$.

A oportunidade de estar em casa por um período de seis meses pode cooperar positivamente para o AME. A mãe em casa com a criança favorece a maior duração do AM por estreitar o vínculo da mãe com a criança proporcionando a continuação e exclusividade do AM. Esse assunto também contribui para aumentar o tempo de licença a maternidade para mães trabalhadoras de quatro para seis meses. Destaca-se como um papel crucial para o AM a enfermagem comprometida com esse programa de incentivo ao AM, dando destaque para os fatores nutricional, imunológico, comportamental, psicológicos e emocionais sobre a amamentação ${ }^{1,6,7}$.

Em 1994, para organizar o modelo de atenção no espaço político-operacional, o Ministério da Saúde lançou o Programa de Saúde da Família (PSF). Em 1998 esse programa passou a ser chamado de Estratégia de Saúde da Família (ESF), que tem o objetivo de implementar os princípios do Sistema Único de Saúde (SUS), integralidade, universalidade, equidade e participação social, e inclui como uma atividade atribuída à equipe de Saúde da Família a visita domiciliar, que é um instrumento fundamental no contexto da ESF e na continuidade da assistência ou atenção domiciliar ${ }^{2,3}$.

A crença do leite insuficiente está pautada na insegurança materna em relação a sua capacidade de produzir leite no volume adequado para atender às necessidades da criança e no choro do bebê, que geralmente é associado à fome. A insegurança materna se manifesta nas falas, "meu leite é pouco, insuficiente, fraco, meu leite secou" o que acaba trazendo a introdução precoce de água, chás e outros alimentos ${ }^{8}$.

Conforme Marques et al. ${ }^{8}$, a hipogalactia é um fenômeno raro, todas as mulheres produzem leite em quantidade suficiente para suprir as demandas do bebê, desde que elas demonstrem o desejo de amamentar e posicionem a criança de forma correta durante $\mathrm{o}$ ato de aleitar. Enfermeiros de atenção primária têm um papel importante no cuidado e acompanhamento das gestantes e mães, para promoção de saúde materna e infantil. A maioria das nutrizes considera o choro como uma manifestação de fome da criança e geralmente opta pelo oferecimento do seio nessas ocasiões. Contudo, o choro da criança pode ser ocasionado pelas condições climáticas (frio ou calor), fraldas sujas e/ou cólicas ${ }^{8}$.

São prevenidas com o AM muitas mortes de crianças no segundo ano de vida, e se a amamentação fosse praticados por dois anos ou mais, muitos casos de sobrepeso e obesidade poderiam ser evitados em pré-escolares. A maior duração do AM está relacionada com a melhora do desempenho cognitivo do indivíduo. Estima-se que para a mulher, cada mês de amamentação ofereça uma redução de 4,3\% do risco de câncer de mama, 15\% do risco de diabetes mellitus, $2 \%$ menos riscos de câncer de ovário ${ }^{7,9,10}$.

A OMS é a favor de que o AM seja um fator de prevenção contra a obesidade infantil. A presença de compostos bioativos no leite humano e diferenças na regulação da saciedade e na ingestão de proteínas seriam mecanismos de diminuição do risco em crianças amamentadas. Um dos compostos bioativos é a leptina, que está presente no leite materno, regula o apetite e o balanço energético, sendo em crianças amamentadas um dos fatores de proteção contra a obesidade. Crianças alimentadas com fórmulas infantis tem excessiva ingestão de proteínas, o que poderia induzir a obesidade; a ingestão proteica acima das necessidades estimula a secreção de insulina e do fator de crescimento semelhante à insulina, aumentando a atividade adipogênica e a diferenciação de adipócitos ${ }^{5-7}$.

Relações entre familiar e parturiente podem implicar no processo do $\mathrm{AM}$, e não se restringe às orientações clássicas de vantagens e técnicas do AM. O que permite ao enfermeiro entender a amamentação como uma prática de elementos definidos e uma prática social na qual a protagonista do AM é a mulher ${ }^{11}$. O objetivo deste estudo foi avaliar as percepções das mães submetidas à primeira consulta puerperal através de um questionário quantitativo em relação ao aleitamento materno.

\section{MÉTODOS}

Trata-se de um estudo descritivo de caráter quantitativo, realizado no Centro de Saúde Escola Capuava. A amostra foi composta por 29 mães submetidas à primeira consulta puerperal. A coleta de dados foi realizada após a autorização do Comitê de Ética e Pesquisa com Seres Humanos da Faculdade de Medicina do ABC $\left(n^{\circ}\right.$ 281.205). Para a coleta de dados, inicialmente foi enviado uma 
carta-ofício, juntamente com o projeto de pesquisa, à gerente de enfermagem e ao diretor do local a ser pesquisado, solicitando a autorização para a realização do estudo. Para a coleta de dados foi utilizado um questionário, aplicado após o grupo de primeira consulta puerperal realizado na Unidade Básica de Saúde (UBS).

O estudo utilizou seres humanos, portanto, obedecendo a Resolução n 196/96 do Ministério da Saúde. A presente resolução fundamenta-se nos principais documentos internacionais que estabelecem declarações e diretrizes sobre pesquisas que envolvem seres humanos. Essa resolução incorpora, sob a ótica do indivíduo e das coletividades, os quatro referenciais da bioética: autonomia, não maleficência, beneficência e justiça, entre outros, e visa assegurar os direitos e deveres que dizem respeito à comunidade científica, aos sujeitos da pesquisa e ao Estado.

\section{RESULTADOS}

Na Tabela 1, a idade média das mães corresponde a 26 anos, com desvio padrão (DP) de 5 anos (mínima de 16 e máxima de 37 anos), 10,3\% dessas mães eram adolescentes ( $<20$ anos). A média de filhos foi de 1,8 com $\mathrm{DP}=0,9 \%$, sendo o mínimo de 1 e o máximo de 5 filhos; $17(58,6 \%)$ mães realizaram cesárea, $12(41,4 \%)$ realizaram parto normal, 1 mãe $(3,4 \%)$ relatou que teve intercorrência no parto com hipertensão arterial sistêmica (HAS), 18 (62,1\%) mães tinham ensino médio completo, $11(37,9 \%)$ tinham ensino médio incompleto, 16 (55,2\%) mães são casadas, 2 (6,9\%) mães são solteiras, 11 $(37,9 \%)$ mães têm união estável, $15(51,7 \%)$ mães trabalham e $14(48,3 \%)$ mães não trabalham.

$\mathrm{Na}$ Tabela 2, observa-se que foram amamentados na sala de parto $20(69,0 \%) \mathrm{RN}$, e $9(31,0 \%) \mathrm{RN}$ não receberam AM; $4(13,8 \%)$ mães possuem mamilos invertidos, 3 (6,9\%) mães possuem mamilos planos e $23(79,3 \%)$ mães possuem mamilos protusos; $13(44,0 \%)$ mães apresentaram fissuras, 16 (55,2\%) mães não apresentaram fissuras; 2 (6,9\%) mães realizam limpeza com água, $1(3,4 \%)$ mãe faz a higiene com água e leite materno, 5 (17,2\%) mães realizam limpeza com leite materno, $2(6,9 \%)$ mães realizam limpeza com leite materno e realizam massagem, 2 (6,9\%) mães realizam limpeza com leite materno e realizam ordenha, $1(3,4 \%)$ mãe realiza massagem, $4(13,8 \%)$ mães utilizam pomada, $1(3,4 \%)$ mãe utiliza pomada e leite materno e $11(37,9 \%)$ mães relataram não realizar nenhum cuidado; 3 (10,3\%) mães amamentam de 2 a 3 horas, $9(31,0 \%)$ mães amamentam de 2 em 2 horas, 7 (24,1\%) mães amamentam de 3 em 3 horas, 8 (27,6\%) mães amamentam de hora em hora e $2(6,9 \%)$ mães amamentam por livre demanda; 25 (89,3\%) RN foram relatados com pega correta e $3(10,7 \%)$ RN com pega inadequada.

$\mathrm{Na}$ Tabela 3, observa-se que $28(96,6 \%)$ mães relataram que tiveram todas as informações necessárias no pré-natal e puerpério, 6 (20,7\%) mães relataram que acham que o AME preconizado pela OMS é de até 2 anos, $20(69,0 \%)$ mães
Tabela 1: Distribuição de variáveis maternas e tipo de parto de mães do Centro de Saúde-Escola Capuava. Santo André, 2013

\begin{tabular}{|c|c|c|c|}
\hline Variável & & $\mathbf{n}$ & $\%$ \\
\hline \multirow{3}{*}{ Mães } & $\begin{array}{c}\text { Adolescentes } \\
<20 \text { anos }\end{array}$ & 3 & 10,3 \\
\hline & $\begin{array}{c}\text { Mulheres } \\
20 \text { a } 29 \text { anos }\end{array}$ & 20 & 69,0 \\
\hline & $\begin{array}{c}\text { Mulheres } \\
30 \text { a } 37 \text { anos }\end{array}$ & 6 & 20,7 \\
\hline \multirow{2}{*}{ Tipo de parto } & Cesárea & 17 & 58,6 \\
\hline & Normal & 12 & 41,4 \\
\hline \multirow{2}{*}{ Escolaridade } & $\begin{array}{l}\text { Ensino médio } \\
\text { completo }\end{array}$ & 18 & 62,1 \\
\hline & $\begin{array}{l}\text { Ensino médio } \\
\text { incompleto }\end{array}$ & 11 & 37,9 \\
\hline \multirow{3}{*}{$\begin{array}{l}\text { Situação } \\
\text { conjugal }\end{array}$} & Casada & 16 & 55,2 \\
\hline & Solteira & 2 & 6,9 \\
\hline & União estável & 11 & 37,9 \\
\hline \multirow{2}{*}{ Trabalho } & Sim & 15 & 51,7 \\
\hline & Não & 14 & 48,3 \\
\hline Total & & 29 & 100,0 \\
\hline
\end{tabular}

Tabela 2: Distribuição de variáveis relacionadas às características cuidados com as mamas e práticas de aleitamento materno, de mães do Centro de Saúde-Escola Capuava. Santo André, 2013

\begin{tabular}{|c|c|c|c|}
\hline Variável & & $\mathbf{n}$ & $\%$ \\
\hline \multirow{2}{*}{$\begin{array}{l}\text { Mamou na } \\
\text { sala de parto }\end{array}$} & Sim & 20 & 69,0 \\
\hline & Não & 9 & 31,0 \\
\hline \multirow{3}{*}{ Mamilos } & Invertidos & 4 & 13,6 \\
\hline & Planos & 2 & 6,8 \\
\hline & Protusos & 23 & 78,2 \\
\hline \multirow{2}{*}{ Fissuras } & Sim & 13 & 44,8 \\
\hline & Não & 16 & 55,2 \\
\hline \multirow{10}{*}{ Cuidados } & Creme hidratante e leite materno & 1 & 3,4 \\
\hline & Higiene com água & 2 & 6,9 \\
\hline & Higiene com água e leite materno & 1 & 3,4 \\
\hline & Leite materno & 4 & 13,8 \\
\hline & Leite materno e massagem & 2 & 6,9 \\
\hline & Leite materno e ordenha & 2 & 6,9 \\
\hline & Massagem & 1 & 3,4 \\
\hline & Nenhum cuidado & 11 & 37,9 \\
\hline & Pomada e leite materno & 1 & 3,4 \\
\hline & Uso de pomada & 4 & 13,6 \\
\hline \multirow{5}{*}{$\begin{array}{l}\text { Quanto } \\
\text { tempo } \\
\text { amamenta }\end{array}$} & 2 a 3 horas & 3 & 10,3 \\
\hline & 2 em 2 horas & 9 & 31,0 \\
\hline & 3 em 3 horas & 7 & 24,1 \\
\hline & Hora em hora & 8 & 27,6 \\
\hline & Livre demanda & 2 & 6,9 \\
\hline \multirow{2}{*}{ Pega correta } & Sim & 26 & 89,7 \\
\hline & Não & 3 & 10,3 \\
\hline Total & & 29 & 100,0 \\
\hline
\end{tabular}

Tabela 3: Distribuição de variáveis sobre a percepção das mães em relação ao aleitamento materno exclusivo do Centro de SaúdeEscola Capuava. Santo André, 2013

\begin{tabular}{|l|c|c|c|}
\hline Variável & & $\mathbf{n}$ & $\%$ \\
\hline \multirow{2}{*}{ Teve todas as informações } & Sim & 28 & 96,6 \\
\cline { 2 - 4 } & Não & 1 & 3,4 \\
\hline \multirow{2}{*}{ Organização Mundial da } & Até 2 anos & 6 & 20,7 \\
\hline Saúde preconiza? & Até 6 meses & 20 & 69,0 \\
\hline Notal & Não sabe & 3 & 10,3 \\
\hline & & & 100,0 \\
\hline
\end{tabular}


relataram que é exclusivo até 6 meses e $3(10,3 \%)$ mães não sabem o período preconizado pela OMS.

Na Tabela 4, observa-se que 2 mães (6,9\%) relataram que pretendem introduzir precocemente líquido, 13 (44,8\%) mães pretendem introduzir precocemente o uso de chupetas para seu $\mathrm{RN}$ e $9(31,0 \%)$ mães introduziram precocemente mamadeira para seu $\mathrm{RN}$.

\section{DISCUSSÃO}

Observa-se na Tabela 1, que a idade das mães mantém uma média de 26 anos, embora com DP de 5 anos, 3 mães (10,3\%) eram adolescentes ( $<20$ anos), o que nos mostra que os dados presentes neste estudo estão compatíveis com os dados observados pelo Instituto Brasileiro de Geografia e Estatística (IBGE) ${ }^{12}$, que mostrou um decréscimo de mães adolescentes e um aumento de mães com 30 anos de idade.

Observa-se também na Tabela 1, 2 mães (3,4\%) acima de 35 anos de idade. Segundo Senesi et al. ${ }^{13}$, essas mulheres podem ter problemas gestacionais, porém, no presente estudo essas mães não desenvolveram nenhuma intercorrência ${ }^{13,14}$.

$\mathrm{Na}$ mesma tabela, observa-se que as mães possuem uma média de $1,8 \%$ de filhos. A quantidade de filhos deste estudo apresentou médias compatíveis com os dados pesquisados pelo IBGE. Segundo o Censo Demográfico, mães têm em média menos filhos e são mães mais tardiamente, o declínio da fecundidade de acordo com o censo foi observado em todas as regiões brasileiras, o número de filhos nascidos vivos em 2010 foi de 1,86 , inferior quando comparado ao censo de 2000 , que teve uma taxa de 2,38 filhos ${ }^{12}$.

$\mathrm{Na}$ Tabela 1 constam 11 mães com ensino médio incompleto e 18 com ensino médio completo, o índice de mães com ensino médio incompleto não ultrapassa os índices de mães com escolaridade completa, a baixa escolaridade é um fator importante. Com base na literatura, o nível de escolaridade faz muita diferença para o aprendizado, visto que mães com menos estudos têm maior dificuldade de compreensão. Dessa forma,

Tabela 4: Distribuição de variáveis de introdução precoce de líquidos ou chás, chupeta e mamadeira em relação ao aleitamento materno de mães do Centro de Saúde-Escola Capuava. Santo André, 2013

\begin{tabular}{|l|c|c|c|}
\hline Variável & & $\mathbf{n}$ & $\%$ \\
\hline Introdução precoce & Sim & 24 & 83,8 \\
\hline \multirow{2}{*}{ Líquidos ou chás } & Não & 5 & 17,2 \\
\hline & Sim & 2 & 6,9 \\
\hline Chupeta & Não & 27 & 93,1 \\
\hline Mamadeira & Sim & 13 & 44,8 \\
\hline Total & Não & 16 & 55,2 \\
\hline & Sim & 9 & 31,0 \\
\hline & Não & 20 & 69,0 \\
\hline
\end{tabular}

contribuem com o desmame precoce, comparadas às mães que possuem nível de escolaridade maior, que demonstram melhor compreensão, promovendo menor risco de desmame ${ }^{15}$.

No que tange aos dados encontrados no SUS, de que mulheres mais escolarizadas são mães mais tarde e têm menos filhos, é um fato a escolaridade ser um fator condicionante importante no comportamento da fecundidade feminina, sendo que mães com ensino incompleto possuem mais filhos do que mães com ensino completo, no entanto, este estudo contraria a literatura, pois as mães presentes neste estudo possuem uma média de filhos de 1,8 variável compatível com as pesquisas do $\mathrm{IBGE}^{12}$.

Na Tabela 1, a quantidade de mães em união estável (11 mães, $37,9 \%$ ) é comparável à quantidade de mães casadas (16 mães, 55,2), resultado compatível com dados das pesquisas do IBGE. Conforme o censo 2010, os casamentos formais cedem espaço às uniões consensuais, em 2000 foi observada uma taxa de $28,6 \%$ de uniões consensuais, já em 2010 essa taxa teve um aumento para 36,4\%. Houve também um declínio na quantidade de casamentos, sendo que em 2000 obteve-se uma taxa de 49,4\% e em 2010 essa taxa foi reduzida para $42,9 \%{ }^{12}$.

No presente estudo, a variável sobre situação conjugal das mães (Tabela 1) tem resultados positivos para o $\mathrm{AM}$, pois a maioria das mães têm o companheiro presente, sendo que apenas duas mães são solteiras. Alguns estudos trazem a importância do companheiro como um suporte ao AM e prevenção de traumas mamilares. Com relação à situação conjugal, segundo o estudo de Coca et al. ${ }^{16}$, confirmou-se que a ausência do companheiro foi um fator associado ao trauma mamilar. Não existem pesquisas que relacionem essa variável com traumas mamilares, mas o companheiro tem sido descrito como importante para o suporte e apoio ao AM; a ausência do companheiro pode deixar a mulher insegura e dificultar o AM. A situação conjugal e a idade materna estão relacionadas ao fato de que mulheres sem companheiros não possuem um apoio social, econômico, emocional e educacional de um parceiro, o que faz com que essas mulheres se tornem mais vulneráveis do que as adultas com companheiro ${ }^{15,16}$.

Observou-se (Tabela 1) que 15 (51,7\%) mães trabalham, no entanto, vale ressaltar que a maneira como é observado o trabalho e a qualidade de vida nas condições no trabalho, se esse tem benefícios ou não. A mãe exerce influência significativa sobre o desmame precoce, pois se esse é condizente com as leis trabalhistas, pode não interferir no $\mathrm{AME}$, mas se não levado em consideração o fato do comprimento de leis trabalhistas, pode influenciar negativamente sobre o AME no decorrer desses seis meses. Conforme Niquini et al. ${ }^{15}$, existe uma associação negativa da introdução precoce de leite artificial relacionada ao trabalho materno formal e com não ter trabalho remunerado, porque as mães que não trabalham não são obrigadas a se afastarem de seus filhos e as mães com trabalho formal, segundo a Consolidação das Leis do Trabalho, têm direito à licença maternidade de 120 dias e, até que o filho complete 180 dias, a 2 descansos diários de meia hora, de 
maneira que são menos vulneráveis à introdução precoce de leite artificial. Porém, nas camadas mais pobres, onde é maior a informalidade no emprego, não há o benefício da licença maternidade e a mãe pode se ver obrigada a desistir do AME para permitir seu sustento e de seu filho, visto que o retorno ao trabalho afasta as mães de seus bebês por cerca de oito horas diárias, o que dificulta a manutenção do AM até seis meses e propicia a maior introdução de leite artificial e desmame pecoce $\mathrm{e}^{15,17,18}$.

Observa-se na Tabela 2, que foram amamentados na sala de parto $20(69,0 \%) \mathrm{RN}$, e $9(31,0 \%) \mathrm{RN}$ não receberam $\mathrm{AM}$. O AM na primeira hora de vida é fator importante, pois reduz a mortalidade infantil, garante a proteção à criança contra infecções, transmite através do colostro imunoglobulinas e interleucinas para a proteção imunológica da criança. Cada fase do leite, até chegar a fase madura, transmite elementos essenciais para garantir proteção da crianças como nos mostra a literatura19. Segundo a OMS, a amamentação na primeira hora de vida é reconhecida como um importante componente na promoção, proteção e apoio ao AM, devendo ser implementada como rotina hospitalar no conjunto dos países no intuito de reduzir a mortalidade neonatal e atingir as metas do componente quatro dos objetivos de desenvolvimento do milênio ${ }^{20-25}$.

Observam-se na Tabela 2 os resultados da variável relacionadas aos mamilos. Obteve-se prevalentes com relação aos mamilos protusos, sendo de $23(79,3 \%)$ mães e apenas $4(13,8 \%)$ com mamilos invertidos e 2 mães $(3,4 \%)$ com mamilos planos. Diante dos resultados de alguns estudos, observa-se que os mamilos malformados e semiprotusos acarretam em lesões mamilares mais facilmente e proporcionam difícil apreensão pela criança. Em estudos sobre fatores associados ao trauma mamilar na maternidade, observou-se que os semiprotrusos e os malformados acarretaram em dificuldades para a apreensão do RN durante a sucção e facilitam a ocorrência de lesões ${ }^{16}$.

Pode-se perceber que os resultados de outros estudos contradizem o presente estudo, pois a proporção de mães com mamilos protusos (23 mães) foi a mais encontrada neste estudo, com uma proporção de 13 mães com presença de fissuras. Independentemente do tipo de mamilo, embora os outros tipos possam gerar mais facilmente a lesão mamilar, as orientações devem ser realizadas com grande importância tanto no período gestacional como durante o puerpério. A importância da orientação diante da primiparidade, comparando esse fato com o presente estudo, teve-se $11(37,9 \%)$ mães primíparas, visto que estas mães possuem mais inexperiência frente às técnicas de amamentação, fator que pode levar ao aparecimento de lesões mamilares ${ }^{16}$.

$\mathrm{Na}$ Tabela 3, sobre os resultados relacionados à incidência de fissuras, obteve-se 13 (44,0\%) mães com presença fissuras. Vale ressaltar que 26 mães relataram ter uma pega correta, um fato que torna importante avaliar melhor as mães com relação ao posicionamento, a pega correta, se apresenta-se assimétrica ou não e também avaliar como essa mãe retira o bebê do seio, fatores que devem ser levados em consideração em um posterior estudo. De acordo com Ministério da Saúde, o AME no Brasil ainda mantinha taxas muito baixas, de 23 dias nas capitais, e entre os fatores que contribuem para essa situação está o manejo inadequado do AM. Muitos estudos, segundo Weigert ${ }^{14}$, demonstram que uma boa técnica de AM nos primeiros dias após o parto está associada à duração do AME.

Quanto ao trauma mamilar, identificado como decorrente do posicionamento e pega incorretos da criança durante o aleitamento materno, a incidência da lesão mamilar varia de 11 a $96 \%$ nas mães que amamentam no decorrer da primeira semana após o parto, sendo que 80 a 95\% dessas mães apresentam algum grau de dor mamilar e $26 \%$ apresentam dor extrema, contribuindo negativamente para o tempo da amamentação ${ }^{16}$.

Shimoda17 refere em seu estudo que, segundo a literatura, a lesão de mamilo induzida pela amamentação tem particularidades únicas, causando distúrbios intermitentes para o tecido cutâneo, com redução da taxa de epitelização e mais tempo para a cicatrização, quando comparada a outros tipos de lesões. Segundo a literatura, a causa básica da lesão de mamilo é uma alteração no padrão de sucção do recém-nascido, que pode ser devido à presença de ingurgitamento mamário e uso da chupeta, como fator que predispõe o $\mathrm{RN}$ a realizar sucção inadequada durante a mamada, devido a uma confusão de bicos mudando o padrão de sucção. A lesão interfere na sensação de prazer e satisfação da mulher que amamenta, constituindo uma justificativa para a interrupção do aleitamento, de acordo com a forma como ela enfrenta a situação ${ }^{17}$.

Vale ressaltar que o fator causador das fissuras presentes em 13 mães no presente estudo necessita ser melhor pesquisado. Os cuidados realizados pelas mães, conforme a Tabela 3, com relação à presença de fissuras mamilares foram a utilização de leite materno no seio, higienização com água e algumas mães também relataram a utilização de pomadas indicadas pelos profissionais durante consulta. Segundo Coca et al. ${ }^{16}$, contraindica-se o uso de cremes, óleos, pomadas, bucha e toalha, pois promovem descamação da pele na região mamilo-areolar, tornando a pele mais sensível e predispondo ao aparecimento de trauma mamilar ${ }^{16}$.

Observou- se no estudo de Zorzi ${ }^{18}$ sobre as práticas utilizadas pelas puérperas nos problemas mamários, que foram realizados diversos cuidados com os mamilos embasados em crenças. Muitos chás que foram usados pelas puérperas têm ação calmante e anti-inflamatória, podendo fornecer alívio da dor na fissura mamilar ${ }^{15}$.

Há uma preocupação com o uso de ervas medicinais no tratamento de fissuras, por não saber qual a origem dos produtos e a forma como os chás são preparados, pois podem se tornar porta de entrada de bactérias no local da fissura, podendo levar a complicações como mastite. O mesmo ocorre para mães que utilizam casca de frutas como banana e mamão para tratar as fissuras ${ }^{15}$. 
Na Tabela 2, sobre distribuição de variáveis relacionadas a amamentação das mães, essa não estava embasada em crenças que trouxessem prejuízos ou piora da lesão mamilar, os cuidados realizados pelas mães foi sob orientações feitas pela equipe de enfermagem e pelos médicos que acompanharam as puérperas no decorrer do pré-natal e puerpério. No presente estudo foram observados três binômios com uma pega inadequada. Mesmo diante dessa baixa incidência, vale ressaltar que o profissional de saúde deve realizar uma orientação adequada das mães tanto durante o pré-natal como no período de puerpério, e intervir ao identificar as dificuldades. Segundo Coca ${ }^{16}$, uma das condutas mais importantes é a educação das mulheres, desde a gestação, em relação à técnica correta de $\mathrm{AM}$, a orientação inadequada ou a falta de orientação durante o pré-natal ou pós-parto também é uma causa sugerida na literatura para ocorrência do trauma mamilar ${ }^{16}$.

A maioria das mães (26 mães, 89,7\%) do presente estudo apresentaram uma pega adequada. No entanto, foram observadas 13 mães com fissuras, um resultado que afirma que as fissuras não são decorrentes somente de uma pega não adequada. Também não significa que o posicionamento não está adequado, de acordo com os resultados de outros estudos, mas existem outros fatores que podem levar a fissuras, como por exemplo a retirada do bebê do seio de forma incorreta. De acordo com estudo de Weigert et al. ${ }^{14}$, a melhora da técnica da amamentação resulta em redução de dor e lesões mamilares. Dessa forma, é importante ressaltar, diante do presente estudo, que as orientações quanto à técnica da amamentação devem ser realizadas para todas as mães, independente de apresentarem lesão mamilar, não como observado o estudo de Weigert et $a l .{ }^{14}$, que demonstrou que as orientações são feitas quando o trauma mamilar já existe ${ }^{14}$.

Na Tabela 3, $28(96,6 \%)$ mães relataram que tiveram todas as informações necessárias durante o pré-natal e puerpério, uma mãe $(3,4 \%)$ não teve todas as informações necessárias. Segundo estudo de Hockenberry e Wilson ${ }^{26}$, de 21 mulheres, apenas 6 foram orientadas por enfermeiros durante o pré-natal. Um fato preocupante, pois a assistência de enfermagem durante o puerpério tem que ser realizada de uma maneira efetiva, pois é um período primordial para que se possa desenvolver o cuidar durante a gestação e fortalecer durante o pós-parto.

Os resultados na Tabela 3 , com relação às orientações realizadas durante o pré-natal e puerpério no hospital de referência Hospital da Mulher e na UBS do Centro de Saúde-Escola (CSE) Capuava, mostram resultados positivos, pois as mães relataram que tiveram resoluções de suas dúvidas e orientações, levando à conclusão de que não ficou faltando nenhuma informação.

$\mathrm{Na}$ Tabela 3 observa-se que as mães presentes neste estudo participaram, antes de responderem ao questionário, de um grupo de aleitamento materno realizado na UBS do CSE Capuava. Foi abordado no questionário qual o período necessário do aleitamento materno exclusivo preconizado pelo
Ministério da Saúde. Dentre as 29 mães, 6 (20,7\%) mães relataram que achavam que o período é de até 2 anos, 20 (69,0\%) mães relataram que é exclusivo até 6 meses e 3 (10,3\%) mães relataram que não sabiam qual o período preconizado pelo MS para o AME. Os resultados observados neste estudo mostra que, mesmo diante da realização do grupo, 9 mães não tiveram uma percepção correta sobre qual é o período determinado pela OMS, porém a maioria (20 mães) respondeu corretamente, que o período é de até 6 meses.

$\mathrm{Na}$ Tabela 4, no grupo realizado pela equipe da UBS do CSE Capuava, foram abordadas as questões sobre a utilização de líquidos, mamadeira e chupetas precocemente. Mesmo diante dos fatores apresentados no grupo com relação a uma técnica incorreta de sucção no seio relacionada ao uso de bicos artificiais e riscos de desmame precoce, $24(83,8 \%)$ mães relataram que pretendem realizar a introdução precoce de 1 ou 2 dos seguintes itens: líquidos ou chás, chupetas ou mamadeiras; e $5(17,2 \%)$ mães não pretendem realizar introdução precoce de nenhum dos itens. Observa-se neste estudo que apenas cinco mães tiveram uma percepção adequada dos riscos que podem causar a utilização de líquidos ou bicos precocemente para o seu filho.

Na Tabela 4 observa-se que, mesmo diante do grupo realizado na UBS, 13 (44,8\%) mães pretendem introduzir precocemente o uso de chupetas para seu $\mathrm{RN}$, um resultado que, de acordo com a literatura, demonstra que 13 crianças possuem riscos para desenvolverem uma técnica inadequada de sucção no seio, gerando lesões mamilares e maiores chances de serem desmamadas precocemente. Segundo Shimoda et al. ${ }^{17}$, a causa básica da lesão de mamilo é uma alteração no padrão de sucção do RN, que pode ser devido à presença de uso da chupeta, como fator que predispõe o RN a realizar sucção inadequada durante a mamada, devido a uma confusão de bicos, mudando o padrão de sucção. Na Tabela 4 temos que 9 $(31,0 \%)$ mães pretendem introduzir precocemente mamadeira para seu RN. Essas mães relataram, durante a aplicação do questionário, que pretendem introduzir a mamadeira devido à necessidade de voltarem a trabalhar.

Conclui-se que as orientações e o acompanhamento realizado durante a gestação, puerpério e em domicílio são de suma importância e aos poucos produzem resultados positivos, como mostra o estudo no qual $20(69,0 \%)$ das mães obtiveram como aprendizado um período de até 6 meses de amamentação, o que está de acordo com o objetivo preconizado pelo MS, tendo como um ponto negativo no estudo uma grande porcentagem $(83,8 \%)$ de mães com intuito de introdução precoce de chás, líquidos, chupeta ou mamadeira.

Vale enfatizar que o profissional enfermeiro é uma peça chave fundamental na realização das orientações durante gestação, puerpério e acompanhamento puerperal em domicílio, contribuindo para alcançar as metas e objetivos preconizados pelo MS e solucionar as dúvidas de mães vulneráveis a informações errôneas e sem fundamentos. 


\section{REFERÊNCIAS}

1. Graça LCC, Fiqueiredo MCB, Conceição MTCC. Contributos da intervenção de enfermagem de cuidados de saúde primários para a promoção do aleitamento materno. Rev Latino-Am Enfermagem. 2011;19(2):429-36.

http://dx.doi.org/10.1590/S0104-11692011000200027

2. Bernardi JLD, Jordão RE, Barros Filho AA. Fatores associados à duração mediana do aleitamento materno em lactentes nascidos em município do estado de São Paulo. Rev Nutr. 2009;22(6):867-78. http://dx.doi.org/10.1590/S1415-52732009000600008

3. Rodrigues TMM, Vale LMO, Leitão RAR, Silva RMO, Rocha SS, Pedrosa JIS. A visita domiciliar do enfermeiro à puérpera e ao recém-nascido. Rev Interdiscip. 2011;4(2):21-6.

4. Barros SM. Enfermagem obstétrica e ginecológica: guia para a prática assistencial. 2 ed. São Paulo: Roca; 2009.

5. Boccolini CS, Carvalho ML, Oliveira MIC, Vasconcelos AGG. Fatores associados à amamentação na primeira hora de vida. Rev Saúde Pública. 2011;45(1):69-78. http://dx.doi.org/10.1590/S0034-89102010005000051

6. Ferreira HS, Vieira EDF, Cabral Junior CR, Queiroz MDR. Aleitamento materno por trinta ou mais dias é fator de proteção contra sobrepeso em pré-escolares da região semiárida de Alagoas. Rev Assoc Med Bras. 2010;56(1):74-80. http://dx.doi.org/10.1590/S0104-42302010000100020

7. Martins EJ, Giugliani ERJ. Quem são as mulheres que amamentam por 2 anos ou mais. J Pediatr. 2012;88(1):67-73. http://dx.doi.org/10.2223/JPED.2154

8. Marques ES, Cotta RMM, Araújo RMA. Representações sociais de mulheres que amamentam sobre a amamentação e o uso de chupeta. Rev Bras Enferm. 2009;62(4):562-9.

http://dx.doi.org/10.1590/S0034-71672009000400012

9. Simon VGN, Souza JMP, Souza SB. Aleitamento materno, alimentação complementar, sobrepeso e obesidade em préescolares. Rev Saúde Pública. 2009;43(1):60-9. http://dx.doi.org/10.1590/S0034-89102009000100008

10. Garcia MV, Azevedo MF, Testa JRG, Luiz CBL. A influência do tipo de amamentação nas condições de orelha média de lactentes. Braz J Otorhinolaryngol. 2012;78(1):8-14.

http://dx.doi.org/10.1590/S1808-86942012000100002

11. Souza MHN, Souza IEO, Tocantins FR. A utilização do referencial metodológico de rede social na assistência de enfermagem a mulheres que amamentam. Rev Latino-Am Enfermagem. 2009; 17(3):354-60.

http://dx.doi.org/10.1590/S0104-11692009000300012

12. Instituto Brasileiro de Geografia e Estatística (IBGE). Censo demográfico 2010. Disponível em: http://www.ibge.gov.br/home/ estatistica/populacao/censo2010/. Acesso em: 23 out. 2013.
13. Senesi LG, Tristão EG, Andrade RP, Krajden ML, Oliveira Junior FC, Nascimento DJ. Morbidade e mortalidade neonatais relacionadas à idade materna igual ou superior a 35 anos, segundo a paridade. Rev Bras Ginecol Obstet. 2004;26(6):477-82. http://dx.doi.org/10.1590/S0100-72032004000600009

14. Weigert EML, Giugliani ERJ, França MCT, Oliveira LD, Bonilha A, Espírito Santo LC, et al. Influência da técnica de amamentação nas frequências de aleitamento materno exclusivo e lesões mamilares no primeiro mês de lactação. J Pediatr. 2005;81(4):310-6. http://dx.doi.org/10.1590/S0021-75572005000500009

15. Niquini RP, Bittencourt SA, Lacerda EMA, Leal MC. Fatores associados à introdução precoce de leite artificial, Município do Rio de Janeiro, 2007. Rev Bras Epidemiol. 2009;12(3):446-57. http://dx.doi.org/10.1590/S1415-790X2009000300013

16. Coca KP, Gamba MA, Silva RS, Abrão ACFV. Fatores associados ao trauma mamilar na maternidade. J Pediatr. 2009;85(4):341-5. http://dx.doi.org/10.2223/JPED.1916

17. Shimoda GT, Silva IA, Santos JLF. Características, freqüência e fatores presentes na ocorrência de lesão de mamilos em nutrizes. Rev Bras Enferm. 2005; 58(5):529-34. http://dx.doi.org/10.1590/S0034-71672005000500006

18. Zorzi NT, Bonilha ALL. Práticas utilizadas pelas puérperas nos problemas mamários. Rev Bras Enferm. 2006;59(4):521-6. http://dx.doi.org/10.1590/S0034-71672006000400009

19. Batista KRA, Farias MCAD, Melo WSN. Influência da assistência de enfermagem na prática da amamentação no puerpério imediato. Saúde Debate. 2013;37(96):130-8.

20. Boccolini CS, Carvalho ML, Oliveira MIC, Pérez-Escamilla R. A amamentação na primeira hora de vida e mortalidade neonatal. J Pediatr. 2013;89(2):131-6. http://dx.doi.org/10.1016/j.jped.2013.03.005

21. Oddy WH. Aleitamento materno na primeira hora de vida protege contra a mortalidade neonatal. J Pediatr. 2013;89(2):109-11. http://dx.doi.org/10.1016/j.jped.2013.03.012

22. Silva EP, Lima RT, Ferreira NLS, Costa MJC. Pré-natal na atenção primária do município de João Pessoa-PB: caracterização de serviços eusuárias. Rev Bras Saúde Mater Infant. 2013;13(1):29-37. http://dx.doi.org/10.1590/S1519-38292013000100004

23. Silva MBC, Moura MEB, Silva AO. Desmame precoce: representações sociais de mães. REE. 2007; 9(1):31-50.

24. Brasil. Ministério da Saúde. Manual instrutivo das ações de alimentação e nutrição na rede cegonha. Brasília: Ministério da Saúde; 2013.

25. Brasil. Ministério da Saúde. Manual AIDPI neonatal. 3 ed. Brasília: Organização Pan-Americana da Saúde; 2012.

26. Hockenberry MJ, Wilson D. Wong: fundamentos de enfermagem pediátrica. 8 ed. Rio de Janeiro: Elsevier; 2011. 